\title{
Neurologic Sequealae of Hematopoietic Stem Cell Transplantation (HSCT)
}

\author{
Ami J. Shah 1,2,3, Tena Rosser 2,3,4 and Fariba Goodarzian 3,5 \\ ${ }^{1}$ Division of Research Immunology/ Bone Marrow Transplantation, \\ 2Department of Pediatrics, Keck School of Medicine, \\ ${ }^{3}$ The Saban Research Institute of Childrens Hospital Los Angeles, \\ ${ }^{4}$ Division of Neurology, \\ ${ }^{5}$ Department of Pediatric Radiology \\ USA
}

\section{Introduction}

Hematopoietic stem cell transplantation (HSCT) has been used to cure many pediatric patients with both malignant and non-malignant diseases in whom conventional therapy has failed. HSCT is generally performed after the administration of high sublethal doses of chemotherapy or chemoradiotherapy to achieve myeloablation, immunosuppression and eradication of abnormal cells. The use of high dose cytotoxic therapy before HSCT places children at risk for acute and long-term side effects which may differ or be more severe than those seen in children who did not receive HSCT. One important organ that may be damaged from cytotoxic therapies used to treat recipients of HSCT has been the brain.

Survival rates for childhood ALL improved after the introduction of treatments to prevent the development of central nervous system (CNS) leukemia. During the past 25 years, CNS prophylaxis for leukemia has consisted of either intrathecal chemotherapy alone or a combination of both chemotherapy and cranial irradiation. There is a wide range of deficits associated with this CNS prophylaxis. Neurological sequelae include severe leukoencephalopathy to more subtle and mild dysfunction, such as learning disorders and abnormalities that can be seen on CT scan or MRI (Packer R 1986, Brouwers P 1985).

In contrast, patients with malignant brain tumors often present with neurological symptoms of their primary disease such as a) increased intracranial pressure b) problems with balance and cranial nerve findings, which are associated with infratentorial tumors and c) seizures, which are often seen in those with supratentorial tumors. The treatment of malignant brain tumors involves chemoradiotherpay in addition to neurosurgery. The cranial irradiation that these children receive is often more than double that received by patients with acute leukemias. Therefore, the neurological sequelae of patients with this particular malignancy are greater than that seen for patients with a hematological malignancy.

The neurocognitive sequelae following cranial irradiation and chemotherapy for childhood acute leukemia and brain tumors have been well documented (Fletcher et al 1988, Smibert et al 1996, Anderson et al 1997, Stehbens et al 1991, Butler and Copeland 1993, Moleski 2000, Ris and Noll 1994, Mulhern and Butler 2004). However, information regarding the 
impact of HSCT and the neurocognitive function of HSCT recipients is still emerging, especially among patients with genetic diseases and those who have a primary immune deficiency.

The different types of transplants and their complications can add to the neurological complications that follow HSCT. In general, there are three different types of HSCT: 1) autologous, which is used for the treatment of solid tumors and lymphomas, 2) syngeneic and 3) allogeneic, which is used for the treatment of leukemias, genetic diseases and immunodeficiencies.

In this chapter we review both the acute neurological complications that can occur following HSCT and the long-term clinical significance of these complications, especially the neurocognitive outcomes of this therapy.

\section{Neurological sequelae following HSCT}

Neurological complications following HSCT have not been studied well, especially in the pediatric population. The majority of studies have focused upon adult patients A prospective study of 180 adult HSCT patient autopsies (177 allogeneic and 3 autologous) detected neuropathologic abnormalities in over $90 \%$ of the subjects (Bleggi-Torres et al, 2000). The most frequent findings in this study were subarachnoid hemorrhage (32\%), intraparenchymal hemorrhage $(27 \%)$ and fungal infections $(9 \%)$. There were no abnormal findings in $9 \%$ of the autopsies. A smaller series of autopsy studies showed similar findings (Mohrmann et al, 1990). Although there were a high number of patients with nervous system involvement following HSCT, we do not know if these findings led to clinically significant neurological complications.

The incidence of clinical neurologic symptoms varies from $10-40 \%$. Weber et al evaluated 165 pediatric patients following HSCT. Of these patients, $67 \%$ were allogeneic and $33 \%$ were autologous. Of these 165 patients, $24 \%$ developed neurologic complications. The cause of the neurological complications included: infections $(n=10)$, drug toxicity $(n=5)$, cerebrovascular events $(n=2)$, and CNS relapse $(n=2)$. Among the infections, aspergillus and toxoplasmosis were the most frequent pathogens isolated (Weber et al, 2008).

A study of patients with Hodgkin Disease who received an autologous HSCT showed early symptoms of neurological complications such as encephalopathy, seizures, cerebral hemorrhage and psychiatric symptoms (Snider et al, 1994). A separate study of a similar population showed the incidence of clinically significant neurological complications as being 3.2\%. (Guerrero et al, 1999).

The incidence of neurological symptoms varies depending upon 1) the disease and the therapies used to treat that disease prior to HSCT, 2) type of transplant (autologous, syngeneic and allogeneic and the complications associated with the specific type of transplant 3) conditioning therapy (chemotherapy alone versus chemoradiotherapy, 4) immunosuppressive therapies and 5) the infections that may occur from being immunosuppressed.

\section{Impact of disease}

There are various reasons for patients to receive HSCT. Among the common diseases include a) hematological malignancies such as acute leukemia, b) malignant solid tumors 
such as brain tumors and c) nonmalignant diseases such as genetic diseases, immune deficiencies and hemoglobinopathies. All of these diseases can have an impact on the neurological outcome of patients, even without a transplant.

Leukemia patients who are either high-risk patients or have CNS disease, often receive between 1800 or 2400 cGy cranial irradiation for the prophylaxis or treatment of CNS leukemia. Many believe that the threshold between 1400 and 1800 cGy does not have an impact upon neurocognitive function. However, it is known that therapies greater than 1800 cGy appear to affect the neurocognitive function of leukemia patients. In contrast, patients with brain tumors, often receive cranial radiation that can be more than twice that traditionally given in the treatment of ALL. Despite differences in the therapy, there are similar declines that are seen in the neurocognitive function of both groups of patients, especially those who are young at diagnosis.

For patients with non-malignant diseases, the pre-transplant neurological sequelae are often related to the disease. For example, patients with sickle cell disease often have a history of strokes prior to HSCT, this can impact a patient's neurological status prior to coming to transplant. In addition, patients with hemoglobinopathies who are on hypertransfusion protocols, may have evidence of iron overload that may involve the brain. Patients with genetic diseases such as adrenoleukodystrophy (ALD) and Krabbe's disease often have disease specific neurological findings prior to HSCT. These patients have lesions in their CNS that can affect both the motor and mental development of these patients. Although there may be some improvement following HSCT, in general these changes do not resolve completely.

Patients with immunodeficiency, such as severe combined immunodeficiency (SCID) or Wiskott Aldrich Syndrome, often have had serious life threatening infections prior to their diagnosis, which may impact their overall neurological function. Therefore, it is important to assess patients both before and after HSCT to really understand the impact of HSCT upon neurological function.

\section{Impact of type of transplant}

Patients who receive an allogeneic transplant are thought to have increased neurologic side effects compared to those receiving an autologous transplant. However, a retrospective study of 425 (mostly adult patients) found that the incidence of neurologic complications was similar in both autologous and allogeneic patients (Saiz et al ,2004). The complications that were seen varied depending upon the type of disease and type of transplant. For example, patients with Acute Myelogenous Leukemia (AML) receiving an autologous transplant developed more subdural hematomas due to prolonged thrombocytopenia; whereas, patients with central nervous system (CNS) infections were more common in those receiving an allogeneic transplant due to prolonged immunosuppression.

Allogeneic transplant recipients are vulnerable to developing graft versus host disease (GVHD). The risk is greatest among patients receiving an unrelated transplant despite the stem cell source. There has been one report of possible central nervous system GVHD in two patients. Two patients developed hemiparesis, seizure, encephalopathy and MRI findings of hyperintense white matter lesions on T-2 weighted images. A brain biopsy on one patient 
and an autopsy finding on the other revealed perivascular lymphocytic infiltrates of primarily donor origin. It is difficult to make an unequivocal diagnosis of this entity, since there are a number of other etiologies that may explain these findings. However, physicians should be made aware of this possibility (Kamble, et al, 2007).

The source of stem cells may also affect the neurologic outcomes. There are three different sources of stem cells: bone marrow, cord blood and peripheralb blood stem cells. Patients who receive peripheral blood stem cells often have a delay in platelet recovery, thus increasing the risk of subdural hematomas. Alternatively, patients with cord blood transplants can have delayed engraftment, thus increasing the period of neutropenia or thrombocytopenia. This can either increase the risk of infections or increase the chances of CNS bleeding, both of which can increase neurologic complications.

Neurologic complications have also been reported following the infusion of stem cells. In one report of 179 consecutive patients, 3 developed complications following the infusion of cryopreserved stem cells (Hoyt et al, 2000). The symptoms were global amnesia $(n=1)$, cerebral infarction $(n=2)$. The patients who developed infarcts showed evidence of a cerebral hemorrhage due to thrombocytopenia and the other showed cerebral aspergillus on autopsy. Therefore, although there are sporadic reports of complications due to the infusion of cells, the risk of the stem cell infusion itself is very low.

\section{Impact of conditioning therapy}

Ther pretransplant conditioning therapy consists of either high doses of chemotherapy or total body irradiation (TBI). The high dose chemotherapy often crosses the blood brain barrier and the TBI has a direct cytotoxic effect upon the brain. This pretransplant conditioning regimen and the therapy used for the prophylaxis against graft versus host disease (GVHD) are thought to be responsible for the majority of neurological complications following HSCT. The use of various chemotherapy regimens and the use of TBI vary depending upon the type of disease that is being transplanted. For example, patients with nonmalignant disorders are often treated with high dose busulfan while most patients with acute lymphoblastic leukemia are treated with TBI in addition to a chemotherapeutic agent. All agents can produce some acute neurotoxicities and may even have some late onset neurotoxicities. The most common agents that are used in transplant conditioning regimens and their side effects are shown in Table 1.

The impact of the conditioning regimen generally affects the patients during the first 30 days post-HSCT, or the acute post-transplant period. Complications during this time period include pancytopenia, metabolic abnormalities, coagulopathies, drug toxicities and infections due to neutropenia. During this period, subdural hematomas are common due to thrombocytopenia and /or platelet refractoriness. Many patients also develop endothelial cell damage from alkylators such as cytoxan. This may also increase patient's risk of developing subdural hematomas. Intraparenchymal hemorrhages are less common, but may occur as well. These are usually associated with myeloid leukemias.

During the acute period, patients are severely neutropenic. As a result, HSCT recipients are at risk of developing a variety of infections they include bacterial, viral and fungal infections. Table 2 details the most common neurologic complications that occur postHSCT. 


\begin{tabular}{|c|c|}
\hline Drug & Neurologic Toxicities \\
\hline Busulfan & $\begin{array}{l}\text { Reversible encephalopathy with somnolence, confusion, } \\
\text { decreased alertness, myoclonus, headaches and } \\
\text { hallucinations. Seizures in approximately } 10 \% \text { of patients. } \\
\text { Prophylactic use of antiepileptics is recommended. (De La } \\
\text { Camara et al } 1991 \text { and Vassal et al 1990) }\end{array}$ \\
\hline Carboplatin & $\begin{array}{l}\text { Ototoxicity in over } 80 \% \text { of children with neuroblastoma } \\
\text { (Parsons et al 1998) }\end{array}$ \\
\hline Carmustine & $\begin{array}{l}\text { Optic disc and retinal microvaculopathy with variable degrees } \\
\text { of visual loss. Very high doses } 9>1,500 \mathrm{mg} / \mathrm{m} 2 \text { ) can be } \\
\text { associated with severe irreversible encephalopathy (Johnson } \\
\text { et al 1999, Burger et al 1981) }\end{array}$ \\
\hline Cytarabine arabinoside & $\begin{array}{l}\text { Pancerebellar syndrome+/- diffuse encephalopathy with } \\
\text { lethary, confusion, and seizures (Baker et al 1991) }\end{array}$ \\
\hline Etoposide & $\begin{array}{l}\text { Acute confusional state, somnolence, and seizures, which } \\
\text { resolve spontaneously (Leff et al 1988) }\end{array}$ \\
\hline Ifosphamide & $\begin{array}{l}\text { Encephalopathy with lethargy, confusion and seizures in 10- } \\
40 \% \text { of patients. Visual or auditory hallucinations, myoclonus, } \\
\text { or muscle rigidity have been reported, which is usually self } \\
\text { limited, but have been reported to progress to a coma. (Pratt } \\
\text { et al 1990, DiMaggio et al 1994) }\end{array}$ \\
\hline Thiotepa & $\begin{array}{l}\text { Chronic encephalopathy with progressive declines in } \\
\text { cognitive and behaviorial function }\end{array}$ \\
\hline
\end{tabular}

Table 1. Neurologic Toxicity of Commonly Used Drugs in HSCT Conditioning Regimens

One of the major complications of CNS therapies is the development of methotrexate induced leukoencephalopathy. The dose of intravenous methotrexate (not intrathecal methotrexate) correlates with the development of leukoencephalopathy. The incidence of this phenomenon is $16-69 \%$. Patients may have no neurological symptoms. Methotrexate induced Leukoencephalopathy does not progress to progressive multifocal leukoencephalopathy ((Knaap et al 2005, Pande et al 2006, Reddick et al 2005). 


\begin{tabular}{|c|c|c|c|}
\hline & $<30$ days & 30-100 days & $>100$ days \\
\hline \multirow[t]{4}{*}{ Infections } & \multicolumn{3}{|c|}{ Fungus (aspergillus,candida, etc) $\rightarrow \rightarrow \rightarrow \rightarrow \rightarrow \rightarrow$} \\
\hline & \multicolumn{2}{|c|}{ Virus (HHV6 and CMV) } & Herpes Zoster \\
\hline & & Toxoplasmosis & PML (JCV) \\
\hline & $\begin{array}{l}\text { Gram negative } \\
\text { bacteria }\end{array}$ & Gram + bacteria & $\begin{array}{l}\text { Encapsulated bacterial } \\
\text { infections }\end{array}$ \\
\hline $\begin{array}{l}\text { Drug induced } \\
\text { neurotoxicity }\end{array}$ & $\begin{array}{l}\text { 1) Cyclosporine or } \\
\text { tracrolimus } \\
\text { induced } \\
\text { encephalopathy } \\
\text { (PRES) } \\
\text { 2) Methotrexate } \\
\text { encephalopathy } \\
\text { 3) Chemotherapy } \\
\text { related side effects }\end{array}$ & $\rightarrow$ & $\begin{array}{l}\text { Multifocal } \\
\text { leukoencephalopathy }\end{array}$ \\
\hline $\begin{array}{l}\text { Vascular } \\
\text { complications }\end{array}$ & $\begin{array}{l}\text { 1) Subdural } \\
\text { hemorrhage, } \\
\text { 2) intracranial } \\
\text { hemorrhage, } \\
\text { 3) thrombotic } \\
\text { disease }\end{array}$ & & \\
\hline Post-HSCT & & & $\begin{array}{l}\text { 1) Post-transplant } \\
\text { lymphoproliferative } \\
\text { disease, } \\
\text { 2) relapse or } \\
\text { 3) secondary malignancy }\end{array}$ \\
\hline Causative issue & Neutropenia & $\begin{array}{l}\text { Acute GVHD } \\
\text { and deficiency of } \\
\text { cellular } \\
\text { immunity }\end{array}$ & $\begin{array}{l}\text { Chronic GVHD and } \\
\text { deficiency of both cellular } \\
\text { and humoral immunity }\end{array}$ \\
\hline
\end{tabular}

Table 2. CNS complications following HSCT

Progressive multifocal leukoencephalopathy is a more devastating complication that is differentiated from methotrexate induced leukoencephalopathy by the presence of more extensive areas of white matter disease. Approximately $7 \%$ of patients who receive cranial irradiation and/ or intrathecal chemotherapy prior to HSCT and intrathecal methotrexate following HSCT develop progressive leukoencephalopathy 4-5 months post-HSCT. Clinical manifestations of this problem include dysarthria, confusion, seizures, upper motor neuron 
weakness and coma. Leukoencephalopathy is usually chronic and often fatal. (Bleyer, 1981, Thompson et al, 1986). Leukoencephalopathy with severe neurological sequelae and death have also been attributed to amphotericin B following TBI in transplant recipients (Devinsky et al, 1987). Figure 1 shows the presence of progressive multifocal leukoencephalopathy in an 18 year old patient with ALL in $3^{\text {rd }}$ remission 4 months following an unrelated BMT. The patient had received $1800 \mathrm{cGy}$ of cranial irradiation prior to HSCT for the treatment of his ALL and received 1360 cGy of TBI as part of his HSCT conditioning regimen. The patient developed seizures and confusion and subsequently went into a coma. Lumbar puncture did not reveal any infectious etiology. The MRI shows extensive white matter changes consistent with progressive multifocal leukoencephalopathy.

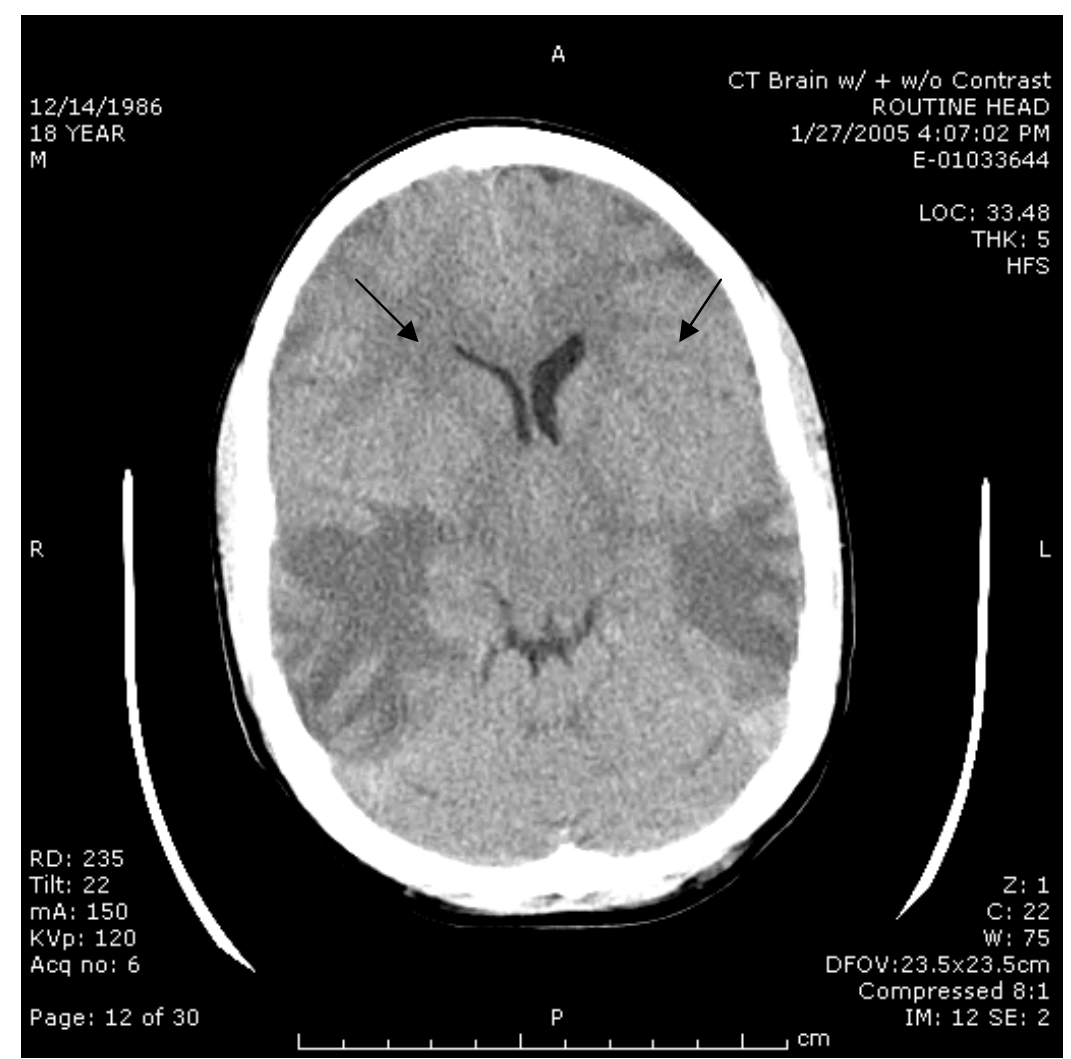

Fig. 1. An 18 year old male with ALL in 3rd remission following an unrelated bone marrow transplant. His conditioning regimen consisted of TBI 1360cGy. Four months post-HSCT he developed seizures and a coma.. An MRI of his head showed bilateral lesions in the deep subcortical white matter of the temporal lobes. The MRI findings are consistent with progressive multifocal leukoencephalopathy

Many patients are unable to tolerate the intensive chemotherapies that are used in myeloablative transplants. Thus many centers have begun to employ the use of reduced intensity conditioning regimens (RIC). RIC often results in increased GVHD, which may 
also increase the neurological sequelae and this may negate the beneficial long term effects that would be seen of decreased drug toxicity. Although it is expected that a RIC will have fewer neurological complications, there are no studies that have been completed in this area.

\section{Impact of immunosuppression}

Patients are often very immunosupressed following HSCT. A variety of complications can occur due to immunosuppression. The second period of transplantation occurs during the time between 30-100 days. During this period, patients may develop GVHD, due to alloreactive donor derived $\mathrm{T}$ cells from the graft attacking nonshared recipient alloantigens in target tissues such as the skin, liver and GI tract. During this time, radiation given during the conditioning period damages the host tissue from the mucosa, liver and other tissues. Activated cells from the damaged recipient tissues secrete inflammatory cytokines, which upregulate expression of recipient antigens. Presentation of recipient antigens to donor T cells occurs and subsequent proliferation and differentiation of these activated $\mathrm{T}$ cells occurs during this time. Activated $\mathrm{CD} 4+\mathrm{T}$ cells expand and generate cytokines promote differentiation of CD8+ $\mathrm{T}$ cells to cytotoxic $\mathrm{T}$ cells, which kill recipient cells and cause further tissue damage.

In order to prevent GVHD, patients are often treated with either Cyclosporin A (CSA) or tacrolimus. Both of these agents can cause neurotoxicity. The most frequent complications seen in patients receiving these agents are tremors (40\%), paresthesias ( $11 \%)$ [Walker et al 1988]. Approximately 5\% of patients develop isolated seizures. Both of these agents can also cause posterior reversible encephalopathy (PRES syndrome). The pathogenesis of PRES is unclear. However, both of these agents disrupt the blood brain barrier or interfere with cerbrovascular autoregulation, resulting in vasogenic edema. This process can rarely progress to irreversible cytotoxic edema (Hinchey et al 1996, Schwarz et al 1995, Mckinney et al 2007). Patients who develop this syndrome develop headache, confusion, blurry vision, visual hallucinations, seizures and motor dysfunction. MRI findings include white matter edema which usually affects the parietal-occipital regions symmetrically and is best seen on fluid- attenuated inversion recovery (FLAIR) sequences. PRES can occur despite normal drug levels. The symptoms of this condition resolve after discontinuation of the drug. The development of PRES does not preclude the safe use of the alternate agent and patients have frequently switched back and forth.

Many HSCT recipients are on corticosteroid therapy, which can also lead to neurological complications. One of the major side effects of corticosteroid therapy includes steroidinduced myopathy, which can occur early in therapy. Steroid-induced myopathy is often characterized by proximal muscle weakness, usually in the hip and neck flexors. Discontinuation of corticosteroids will improve the condition, but that may take many months to achieve. Corticosteroids are also well known to cause a number of psychiatric symptoms such a hallucinations, insomnia, anxiety, mood swings and memory problems.

After one hundred days post-HSCT, chronic GVHD may occur. The immune system generally tends to recover, however if chronic GVHD occurs, there tends to be a prolongation of both cellular and humoral recovery. Patients are at high risk of developing infections with a variety of infections that can include bacterial, viral and fungal infections. Since HSCT recipients are on anti-inflammatory medications such as corticosteroids, it may be difficult for patients to display the classic signs of CNS infections such as fever and 
meningismus. In addition, many patients have other ongoing complications from their transplant that CNS infections are not often considered.

Patients with CNS infections can be grouped into those who have nonfocal generalized CNS dysfunction such as headaches and meningismus or into those with focal findings suggestive of a mass lesion or stroke. In the first month following HSCT, most patients are neutropenic and are at risk of bacterial infections. In the first month following transplant, gram negative bacterial infections are more predominant, but in the later period (30-100 days) of HSCT, gram positive infections predominate. Methicillin-resistant Staphylococcus aureus or epidermidis (MRSA/ MRSE) and Listeria monocytogenes may cause meningitis, encephalitis and ventriculitis.

Viral infections post-HSCT include those who develop adenovirus or Coxsackie virus B4 can also produce encephalitis (Krouwer et al 2003, Cree et al 2003). Acquired viral infections such as with human herpes virus 6 (HHV6) and cytomegalovirus (CMV) infections are also common during this period. Most children develop primary HHV6 infection between 6 months and 5 years of age (Yoshikawa et al 2003, Gorniak et al 2006). After the primary infection, this virus remains latent in the body and reactivates upon immunosuppression of the host. HHV6 often reactivates concurrently with GVHD and can develop in approximately 28\%-78\% of HSCT recipients (Yoshikawa et al 2003, Gorniak et al 2006). Symptoms that have been associated with CNS HHV6 infections include short-term memory loss, mental status changes, fever and headache. The mortality of HHV6 infections is greater than $50 \%$. Figure 2 shows the MRI of a 14 year old female patient with ALL and chronic GVHD. 2 months following HSCT she developed fevers, headaches, seizures and confusion. A CT scan was read as normal, however the MRI showed hyperintensity in the limbic system. A lumbar puncture revealed HHV6 infection and she was treated with foscarnet. This patient recovered from her HHV6 infection, however the mortality of this infection is more than $50 \%$ (Yoshikawa et al 2003, Gorniak et al 2006).

Most pediatric patients have indwelling central venous catheters during their transplant. These patients are at risk of developing fungal infections due to Candida. Candidemia can become disseminated and involve the CNS with septic emboli. Aspergillus infections are the most common fungal infection following HSCT. These often occur when patients are either neutropenic or when their $\mathrm{T}$ cells have not recovered (day 0-100). MRI findings of patients with Aspergillus often show ring enhancing lesions that may have hemorrhage surrounding the lesion. Aspergillus preferentially occurs in the basal ganglia, cerebral hemispheres, and the corpus callosum. Unfortunately, a biopsy of this area is very difficult and treatment is often started empirically. The treatment is usually liposomal amphotericin, which may add to neurological complications post-HSCT. There are newer agents that are also available for the treatment of aspergillus. The mortality of cerebral aspergillosis approaches $85-100 \%$ depending upon the degree of neurological compromise at presentation (Guermazi et al 2003, Miaux et al 1995).

The most common parasitic infection following HSCT is Toxoplasma gondii. Patients present with focal symptoms and mild to severe encephalopathy. MRI findings on these patients show the presence of multiple mass lesions affecting the basal ganglia with minimal to no enhancement. Patients who have not received prophylactic antibiotics with trimethoprim sulfamethoxazole are at risk of developing this infection. 


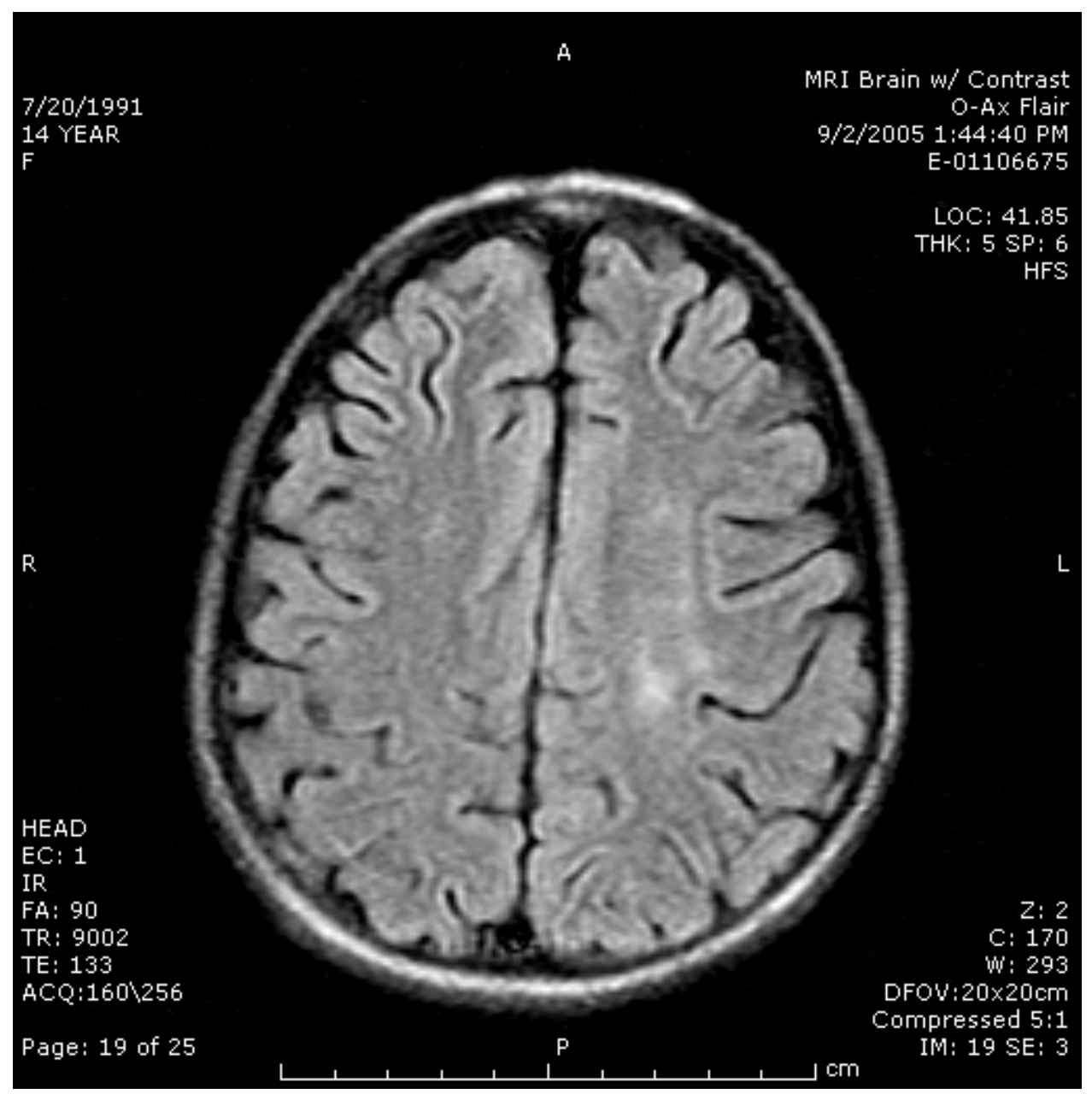

Fig. 2. An MRI of a 14 year old female with ALL in 3rd remission following an unrelated cord blood transplantation. She developed severe graft versus host disease fever, confusion and seizures. A lumbar puncture revealed the presence of HHV6. Flair T2 demonstrates biparietal white matter increased signal intensity more on the left side. This is consistent with HHV6 lesion.

Finally, post-transplant lymphoproliferative disease (PTLD) covers a spectrum that involves benign polyclonal lymphoid hyperplasia to malignant monoclonal lymphoma. Often Ebstein Barr Virus (EBV) is the infectious etiology of the malignant lymphoma. In children, the risk is related to a primary EBV infection in a previously seronegative younger patient (Newell et al, 1996). These patients are usually treated with either reduced immunosuppression or chemotherapy. When PTLD does involve the CNS, the prognosis is poor. 


\section{Neurocognitive function following HSCT}

The potential impact of the disease, intensive therapy, social isolation and altered family dynamics in a young child is uncertain and cannot be studied well in pediatric patients. PotMees (1989) documented the profound psychosocial effects of HSCT on patients and families. Recipients of HSCT, despite the underlying disease for which they are transplanted, often face prolonged periods of time in the hospital. Many do not attend school on a regular basis. During the time that they are receiving therapy, they often have some malnutrition due to nausea and vomiting from the therapy to treat their underlying disease. Even after their therapy is completed, some children have an adaptive school program. After HSCT, many children do not have a normal immune system for a long period after HSCT. As a result, they are not involved with extracurricular activities like other age-matched peers.

One would expect that HSCT would increase the neurocognitive deficits seen in pediatric leukemia survivors. The current studies of neurocognitive functioning upon HSCT recipients have yielded mixed results. Most studies of neurocognitive function upon HSCT recipients contain patients with all diseases (malignant and non-malignant), varying types of transplants and conditioning regimens and different age groups. This makes it difficult to interpret the impact of HSCT upon specific disease groups.

Some studies have shown no significant differences in intellectual functioning in patients who are pre-HSCT versus those who are one-year post-HSCT evaluations, except for those patients who have been younger at diagnosis (Kaleita et al 1989, Kramer et al 1992, Simms et al 1998, Phipps et al 1995, Simms et al 2002, Phipps et al 2000, Chou et al 1996, Phipps et al 2008). Whereas, other studies have reported that those patients who receive cranial irradiation have declining neurocognitive function in terms of IQ, achievement, memory and fine motor skills (Cool et al 1996, Smedler et al 1995, Said et al , Kramer et al 1997, Shah et al 2008).

Consistently, all of these previous studies have shown that a younger age at diagnosis and treatment have resulted in significant declines in neurocognitive function In addition, deficits in fine motor skills appear to be more pronounced in HSCT recipients who received cranial irradiation at a younger age than those who received cranial irradiation at an older age (Phipps 2000, Cool 1996, Smedler 1990). Since cranial irradiation appears to affect the information processing, memory and attention mechanisms of the brain, patients who have received cranial irradiation (brain tumor patients and those who had CNS leukemia or received propylaxis for CNS leukemia) are at particular risk of developing long-term cognitive deficits.

Phipps et al conducted the largest pediatric trial relating to the neurocognitive function of patients post-HSCT. This prospective study had 102 patients, who received a full battery of tests for up to 3 years post HSCT. In this study, the neurocognitive function (cognitive and academic functioning) was not impacted by HSCT in patients greater than 6 years of age. There was no impact of TBI upon neurocognitive function. The greatest decline in neurocognitive function occurred in those $<3$ years of age. A follow up study done in 2008, increased the population being evaluated to 268 patients. Although the majority of patients had a malignant disease, there were minimal neurocognitive delays. There were subgroups of patients that were increased risk of neurocognitive delays. These subgroups included those who received TBI, recipients of unrelated transplants, and those who developed graft versus host disease (Phipps et al 2008). 
For patients who received HSCT for genetic diseases of immunodeficiencies, the information regarding neurocognitive function post-HSCT is sparser. Most patients with genetic disease have problems due to their underlying disease. Following HSCT, the developmental outcomes vary depending upon the disease that they were transplanted for and their preHSCT performance scores. Prasad et al transplanted 159 pediatric patients with a variety of inherited metabolic disorders. Among patients with MPS I (Hurler's Disease), most have shown continued increases in their neurocognitive skills, with $81 \%$ of them being in age appropriate classes. However, for patients with MPS III (Krabbe's disease), there was less of an impact of HSCT upon neurocognitive function. Most children with Krabbe's disease have severe neurological complications of this disease. Of the surviving patients with Tay-Sachs, there was no impact of HSCT upon their neurocognitive function and the surviving patients are severely debilitated (Prasad 2008).

There have not been any formal studies upon the neurocognitive function of patients with hemoglobinopathies following HSCT. Walters et al recently reported the outcomes of patients receiving HSCT for sickle cell disease. In that study of 55 long-term survivors of histocompatible HSCT, 19 patients developed neurological complications post HSCT, which consisted primarily of seizures. One patient had graft rejection and subsequently developed a second thrombotic stroke. However, no formal neurocognitive testing was done on these patients to determine the long-term clinical impact of transplant on this group of patients (Walters et al, 2009).

Many patients with immunodeficiencies, present to a doctor only after they have had a lifethreatening illness. Since these children are very young at diagnosis, they are usually socially isolated after the diagnosis is made. They are not exposed to their age-matched peers. In addition, they often have a history of chronic infections, especially their respiratory systems.

For patients with immunodeficiencies, there have been only 2 major studies that have focused on this population alone. First, Titman et al reported the results of formalized neurocognitive testing upon 106 patients with immunodeficiencies. This study showed that the underlying genetic disease, presence of ADA deficient SCID and consanguinity were associate with a worse outcome. Age at transplantation $(\leq 3$ years of age versus $>3$ years of age), length of stay in the hospital, and chemotherapy conditioning regimen were not significant factors (Titman, 2008).

Lin et al performed a prospective study on the neurocognitive function of 16 patients with SCID. Although there were significant decreases in the formal neurocognitive test scores, the results showed that these children did learn and acquire developmental milestones, but at a slower rate than their age matched normal peers. There was no impact of age $(\leq 8$ months versus $>8$ months of age), presence of serious infections prior to HSCT, or length of stay in the hospital (Lin, 2009).

\section{Conclusion}

Patients who receive HSCT are at great risk of developing neurological sequelae due to either their primary disease, the therapies used to treat the disease and the complications of these treatments. The complications can be hard to diagnose. These complications can have serious implications for the long-term survivor of HSCT. Formal testing of HSCT recipients neurocognitive function should be required for patients 


\section{References}

[1] Anderson V, Godber T, Smibert E and Ekert H. (1997) Neurobehaviorial sequlae following cranial irradiation and chemotherapy in children: an analysis of risk factors. Pediatr Rehabil 1: 63-76.

[2] Baker WJ, Royer GL JR, Weiss RB: (1991) Cytarabine and neurologic toxicity. J Clin Oncol 9: 679-693.

[3] Bleggi-Torres LF, de Medeiros BC, Werner B, et al. (2000) Neuropathological findings after bone marrow transplantation: An autopsy study of 180 cases. Bone Marrow Transplant 25: 301-307.

[4] Bleyer WA (1981). Neurologic sequelae of methotrexate and ionizing radiation: a new classification. Cancer TreatmentReports 65 (Suppl) 89-98.

[5] Brouwers P, Riccardi R, Fedio P Poplack DG (1985). Long term neuropsychological sequelae of childhood leukemia. Correlation with CT brain scan abnormalities. J Pediatr 106: 723-728.

[6] Brouwers P, Riccardi R, Poplack D, et al (1984). Attentional deficits in long term survivors of childhood acute lymphoblastic leukemia (ALL). J Clin Neuropsych 6: 325-336.

[7] Burger PC, Kamenar E, Schold SC, et al (1981). Encephalomyelopathy following highdose BCNU therapy. Cancer 48:1318-1327.

[8] Butler RW and Copeland DR. (1993) Neuropsychological effects of central nervous system prophylactic treatment in childhood leukemia: methodological considerations. J Ped Psych, 18:319-338.

[9] Chou RH, Wong GB, Kramer JH et al. (1986) Toxicities of total body irradiation for pediatric bone marrow transplantation. Int J Radiat Oncol Biol Phys 34: 843-851.

[10] Cool VA. Long-term neuropsychological risks in pediatric bone marrow transplant: what do we know? Bone Marrow Transplant (1996) 18 Suppl 3: S45-S49.

[11] Cree, BC, Bernardin GL, Hays AP et al. (2003) A fatal case of coxsackie virus B4 meningoencephalitis. Arch Neurol 60: 107-117.

[12] De La Camara R, Tomas JF, Figuera A et al. (1991) High dose busulfan and seizures. Bone Marrow Transplant 7: 363-4.

[13] Devinsky O, Lemann W, Evans AC, et al. (1987) Akinetic mutism in bone marrow transplant recipient following total body irradiation and amphotericin B chemoprophylaxis. A positron emission tomographic and neuropathologic study. Arch Neurol, 44: 414-7.

[14] DiMaggio JR, Brown R, Baile WF, et al. (1984) Hallucinations and ifosfamide indued neurotoxicity. Cancer 73: 1509-1514.

[15] Fletcher JM and Copeland DR (1988) Neurobehavioral effects of central nervous system prophylactic treatment of cancer in children. J Clin Exp Neuropsychology 10: 495538.

[16] Gorniak RJT, Young GS, Wiese DE, Marty FM, Schwarz RB. (2006) MR imaging of human herpes virus -6-associated encephalitis in 4 patients with anterograde amnesia after allogeneic hematopoietic stem cell transplantation. Am J Neuroradiol 27:887-891.

[17] Guermazi A, Gluckman E, Tabti B, Myaux Y (2003) Invasive central nervous system aspergillosis in bone marrow transplant recipients: an overview. Eur Radio 13:1480-1485. 
[18] Guerrero A, Perez-Simon JA, Gutierrez N et al (1999) Neurological complications after autologous stem cell transplantation. Eur Neurol 41:48-50.

[19] Hinchey J, Chaves C, Appignani B, et al. (1996) A reversible posterior leukoencephalopathy syndrome. N Eng J Med 334:494-500.

[20] Hoyt R, Szer J, Grigg A. (2000) Neurological events associated with the infusion of cryopreserved bone marrow and / or peripheral blood progenitor cells. Bone Marrow Transplant 25: 1285-1287.

[21] Johnson DW, Cagnoni PJ, Schossau TM et al (1999) Optic disc and retinal microvasculopathy after high-dose chemotherapy and autologous hematopoietic progenitor cell support. Bone Marrow Transplant 24: 785-792.

[22] Kaleita TA, Shilds D, Tesler A, Feig SA (1989) Normal neurodevelopment in four young children treated with bone marrow transplantation for acute leukemia or aplastic anemia. Pediatrics 83: 753-757.

[23] Kamble RT, Chang CC, Sanchez S, Carrum G (2007) Central nervous system graft versus host disease: a report of two cases and literature review. BMT 39: 49-52.

[24] Kramer JH, Crittendon MR, Halberg FE, et al. (1992) A prospective study of cognitive functioning following low-dose cranial radiation for bone marrow transplantation. Pediatrics 90: 447-450.

[25] Krouwer HG, Wijdicks EF. (2003) Neurologic complications of bone marrow transplantation. Neurol Clin 21: 319-352.

[26] Leff RS, Thompson JM, Daly MB, et al. (1988)Acute neurologic dysfunction after highdose therapy for malignant glioma. Cancer 62:32-35.

[27] Lin M, Epport K, Azen C et al (2009) Long term neurocognitive function of pediatric patients with severe combined immune deficiency (SCID): pre and post hematopoietic stem cell transplant. J Clin Immunol 29: 231-237.

[28] Mckinney AM, Short J, Truwit CL et al. (2007) Posterior reversible encephalopathy syndrome: incidence of atypical regions of involvement and imaging findings. Am J Radiol 189:904-912.

[29] Miaux Y, Willimas M, Guermazi A et al. (1995) MR of cerebral aspergillosis in patients who have had bone marrow transplantation Am J Neurradiol 16:555-562.

[30] Mohrmann RL, Mah V Vintners HV: (1990) Neuropathologic findings after bone marrow transplantation: An autopsy sudy. Hum Pathol 21:630-639.

[31] Moleski M. (2000) Neuropsychological, neuroanatomical, and neurophysiolical consequences of CNS chemotherapy for acute lymphoblastic leukemia. Arch Clin Neuropsychol 5: 603-630.

[32] Mulhern RK and Butler RW (2004). Neurocognitive sequelae of childhood cancers and their treatment. 7: 1-14.

[33] Newell KA, Alonso EM, Whitington PF et al. (1996) Posttransplant Lymphoproliferative disease in pediatric liver transplantation. Interplay between primary Ebstein -Barr virus infection and immunosuppression. Transplantation. 62:370-375, 1996.

[34] Packer RJ, Zimmerman RA, Bilaniuk LT (1986) Magnetic resonance imaging in the evaluation of treatment-related central nervous system damage. Cancer 58: 635-640.

[35] Parsons SK, Neault MW, Lehman LE, et al (1998) Severe ototoxicity following carboplatin-containing conditioning regimen for autologous marrow transplantation for neuroblastoma. Bone Marrow Transplant 22:669-674. 
[36] Phipps S, Brenner M, Heslop H,. Krance R, Jayawardene M, Mulhern R (1985) Psychological effects of bone marrow transplantation on children and adolescents: a preliminary report of a longitudinal study. Bone Marrow Transplant 15:829-835.

[37] Phipps S, Dunaveant M, Srivastava DK, Bowman L, Mulhern R (2000) Cognitive and academic functioning in survivors of pediatric bone marrow transplantation. J Clin Oncol 18: 1004-1011.

[38] Phipps S, Rai SN, Leung WH, et al. (2008) Cognitive and academic consequences of stem cell transplantation in children. J Clin Onc 26: 2027-2033.

[39] Pott-Mees CC (1989): the Psychological Aspects of Bone Marrow Transplantation in Children. Delft, The Netherlands, Eburon,.

[40] Prasad VK, Mendizabal A, Parikh SH et al. (2008) Unrelated donor umbilical cord blood transplantation for inherited metabolic disorders in 159 pediatric patients from a single center: influence of cellular composition of the graft on transplantation outcomes. Blood 112: 2979-2989.

[41] Pratt CB, Goren MP, Meyer WH, et al (1990) Ifosfamide neurotoxicity is related to previous cisplatin treatment for pediatric solid tumors. J Clin Oncol 8: 1399-1401.

[42] Ris MD, and Noll RB. (1994) Long-term neurobehaviorial outcome in pediatric brain tumor patients: review and methodological critique. J Clin Exp Neurolopsych 16: $21-42$.

[43] Saiz A, Graus F (2004): Neurological complications of hematopoietic cell transplantation. Semin Neurol 24: 427-434.

[44] Schwarz RB, Bravo SM, Klufas RA et al. (1995) Cyclosporine neurotoxicity and its relationship to hypertensive encephalopathy: $\mathrm{Ct}$ and MR findings in 16 cases. Am J Radiol 165:627-631.

[45] Shah AJ, Epport K, Azen C et al (2008). Progressive declines in neurocognitive function among pediatric recipients of hematopoietic stem cell transplantation for hematological malignancies. J Pediatr Hematol Oncol. 30:411-418.

[46] Simms S, Kazak AE, Gannon T, Goldwein J, Bunin N (1998) Neuropsychologival ouitcome of children undergoing bone marrow transplantation. Bone Marrow Transplant 22: 181-184.

[47] Simms S, Kazak, AE, Golomb V, Goldwein J. Bunin N (2002) Cognitive behaviorial and social outcome in survivors of childhood stem cell transplantation. J Ped Hem Onc 25: 5-7.

[48] Smedler AC, ringden K Bergman H, Bolme P (1990): Sensory-motor and cognitive functioning in children who have undergone bone amrrow transplantation. Acta Paedr Scan 79: 613-621.

[49] Smibert E, Anderson V, Godber T, Ekert H (1996) Risk factors for intellectual and educational sequelae of cranial irradiation in childhood acute lymphoblastic leukemia. Br J Cancer 73: 825-30.

[50] Snider S, Bashir R, Bierman P (1994) Neurologic complications after high dose chemotherapy and autologous bone marrow transplantation for Hodgkins disease. Neurology 44:681-684.

[51] Stehbens JA, Kaleita TA, Noll RB et al. (1991) CNS prophylaxis of childhood leukemia: What are the long-term neurological, neuropsychological and behaviorial effects? Neuropsycholga Review 2: 1147-177. 
[52] Thompson CB, Sanders JE, Flournoy N et al (1986) The risks of central nervous system relapse and leukoencephalopathy in patients receiving marrow transplants for acute leukemia. Blood 67, 195-9.

[53] Titman P, Pink E, Skucek E, O'Hanlon K et al. (2008) Cognitive and behavioral abnormalities in children after hematopoietic stem cell transplantation for severe congenital immunodeficiencies. Blood 112: 3907-3913.

[54] Vassal G, Deroussent A, Hartmann O, et al (1990). Dose-dependent neurotoxicity of high-dose busulfan in children: A clinical pharmacological study. Cancer Res 50:6203-6207.

[55] Walker RW, Brochstein JA (1988). Neurologic complications of immunosuppressive agents. Neurol Clin 6:261-278.

[56] Walters MC, Hardy K, Edwards S et al (2009). Pulmonary, gonadal and central nervous system status after bone marrow transplant for sickle cell disease. Biol Blood Marrow Transplant. 2009 Oct 9. [Epub ahead of print]

[57] Weber C, Schaper J, Tibussek D et al (2008) Diagnostic and therapeutic implications of neurological complications following paediatric haematopoietic stem cell transplantation. BMT 42: 253-259.

[58] Yoshikawa T (2003) Hujman herpesvirus 6 and -7 infections in transplantation. Pediatr Transplantation 7:11-17. 


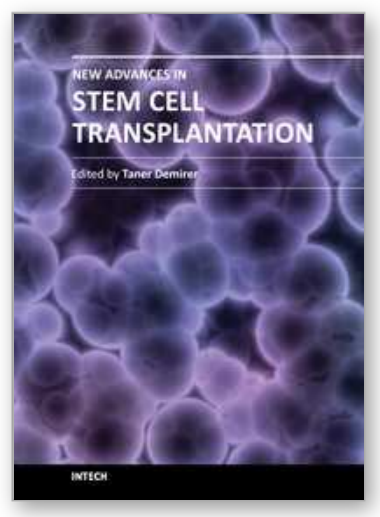

\author{
New Advances in Stem Cell Transplantation \\ Edited by Prof. Taner Demirer
}

ISBN 978-953-51-0013-3

Hard cover, 582 pages

Publisher InTech

Published online 24, February, 2012

Published in print edition February, 2012

This book documents the increased number of stem cell-related research, clinical applications, and views for the future. The book covers a wide range of issues in cell-based therapy and regenerative medicine, and includes clinical and preclinical chapters from the respected authors involved with stem cell studies and research from around the world. It complements and extends the basics of stem cell physiology, hematopoietic stem cells, issues related to clinical problems, tissue typing, cryopreservation, dendritic cells, mesenchymal cells, neuroscience, endovascular cells and other tissues. In addition, tissue engineering that employs novel methods with stem cells is explored. Clearly, the continued use of biomedical engineering will depend heavily on stem cells, and this book is well positioned to provide comprehensive coverage of these developments.

\title{
How to reference
}

In order to correctly reference this scholarly work, feel free to copy and paste the following:

Ami J. Shah, Tena Rosser and Fariba Goodarzian (2012). Neurologic Sequealae of Hematopoietic Stem Cell Transplantation (HSCT), New Advances in Stem Cell Transplantation, Prof. Taner Demirer (Ed.), ISBN: 978953-51-0013-3, InTech, Available from: http://www.intechopen.com/books/new-advances-in-stem-celltransplantation/neurologic-sequelae-of-hematopoietic-stem-cell-transplantation

\section{INTECH}

open science | open minds

\section{InTech Europe}

University Campus STeP Ri

Slavka Krautzeka 83/A

51000 Rijeka, Croatia

Phone: +385 (51) 770447

Fax: +385 (51) 686166

www.intechopen.com

\section{InTech China}

Unit 405, Office Block, Hotel Equatorial Shanghai

No.65, Yan An Road (West), Shanghai, 200040, China

中国上海市延安西路65号上海国际贵都大饭店办公楼 405 单元

Phone: +86-21-62489820

Fax: +86-21-62489821 
(C) 2012 The Author(s). Licensee IntechOpen. This is an open access article distributed under the terms of the Creative Commons Attribution 3.0 License, which permits unrestricted use, distribution, and reproduction in any medium, provided the original work is properly cited. 